\title{
Valuation of 2 - Minute, 4 - Minute, 6 - Minute and 8 - Minute Run - Walk Tests for Male Physical Education Students
}

\author{
Uday N. Manjre \\ H.V.P.M Degree College of physical Education \\ Amravati, India \\ umanjre@ rediffmail.com
}

\begin{abstract}
- this study investigated the validation of 2-minute, 4- minute, 6-minute, and 8-minute Run-walk tests for male Physical Education Students. One hundred and twenty (120) male students of the age range 18-25 years were selected randomly as subjects from different Physical Education College of S.G.B. Amravati University, Amravati. The measured criterion selected for this study was Cooper's 12-minute Runwalk test. Data were collected by administering 2-minute, 4 minute, 6-minute, 8-minute, and 12-minute Run/Walk Tests. To establish the reliability of sunjects used in this study, a Testretest method was employed. In addition, to establish the relationship between the tests of cardiovascular endurance and the criterion test Pearson's products moment, Co-relation statistical technique was employed. Result of this study shows that there is a significant relationship in between cooper's 12minute Run / Walk and 2-minute Run /Walk $(r=0.47), 4-$ minute Run / Walk $(r=0.68), 6$-minute Run / Walk $(r=0.75)$, and 8 - minute Run / Walk $(r=0.78)$
\end{abstract}

Keywords-Cardiovascular Endurance

\section{INTRODUCTION}

Enjoying good health should be considered a perfectly natural phenomenon which is shared by all people who possess normal constitution. Mental and Physical fitness can be enjoyed without a prolonged course of physical training. In the long history of physical education, circulatory respiratory test have been developed and it is utilized by physical educator, the principal users of such tests in physical fitness programmers'. Several attempts have been made over the years and some are still being made to prepare test for cardiovascular fitness. The "Pock Test" was developed in early 1940 for testing American Military personnel, and it became very popular. The main aim of the both the tests was to get the heart rate up.

\section{A. Statement of Research Problem}

This research aims to investigate the validity of 2-minute, 4-minute, 6-minute, and 8-minute Run / Walk test for male Physical Education Students.

\section{B. Purpose of the Study}

The main purpose of this study was to assess the validity of 2 - minute, 4 - minutes, 6 - minutes, and 8 - minutes Run / Walk Test to measure the cardiovascular fitness of male Physical Education students.

\section{Significance of the Study}

1) The findings of this study can be used for large numbers of subjects who are to be tested for cardiovascular endurance.

2) The results of this study would be of help to large scale project undertaken, to develop norms for 6- minute and 8- minute Run/Walk tests for different populations.

3) This study could be help to reduce the duration of time for Run / Walk tests.

4) This study could be used to induce sedentary people to take up running for reduced duration of time for cardiovascular efficiency.

\section{HYPOTHESIS}

Based on related literatures review, discussion with experts, and own understanding, it was hypothesized that 2 minute, 4- minute, 6- minute, and 8- minute Run /Walk Test will be valid to measure cardio vascular fitness of professional students of Physical Education..

\section{METHODOLOGY}

\section{A. Delimitations}

1) This study was delimited to 120 male students of Bachelor of Physical Education from different Physical Education College of S.G.B. Amravati University, Amravati.

2) This study was further delimited to only male students of age range $18-25$ years.

\section{B. Limitations}

1) The subjects used in this study were from different states of India. Their diet and participation in various activities as a part of their professional preparation could not be controlled by the scholar.

2) The subjects i.e. the students of Bachelor of Physical Education have different types of activities according to their college curriculum, and their time-table wheels could not be controlled by the scholar Units

\section{Selection of the subjects}

One hundred and twenty (120) male students of the age range 18-25 years were selected for this study randomly as 
subjects from different Physical Education Colleges of S.G.B. Amravati University, Amravati.

\section{D. . Selection of test and Criterion Measures}

The test and Criterion measure used for this study was Cooper's 12- minute Run / Walk Test.

\section{E. Selection of other Duration of Tests}

The test and Criterion measure used for this study was Cooper's 12- minute Run / Walk Test.

\section{F. Collection of Data}

The data pertaining to this study were collected from the selected subjects by administering the aforesaid tests. Before the collection of the research data, the research scholar explained the purpose of the study to the subjects so that they will put in their best. The tests were conducted at the 400 meter cinder track.

\section{ANALYSIS OF DATA}

\section{A. Findings}

To establish the reliability of subjects, Test- retest method was employed. The data was subjected to statistical treatment which compared the Pearson's product moment correlation computed between the tests of cardiovascular endurance and the criterion test. Coefficient of variability was used to assess the relative variability of scores in the test of cardiovascular endurance.

Co-efficient of correlation was computed for the two sets of score in each test, the coefficients are presented in Table 1.

TABLE I. COEFICIENTS OF RELIABILITY OF TESTS

\begin{tabular}{|l|c|}
\hline \multicolumn{1}{|c|}{ Test } & "r" \\
\hline Cooper's 12- minutes Run/Walk Test & 0.96 \\
\hline 8- minute Run / Walk Test & 0.96 \\
\hline 6- minute Run / Walk Test & 0.89 \\
\hline 4- Minute Run / Walk Test & 0.95 \\
\hline 2- minute Run / Walk Test & 0.94 \\
\hline
\end{tabular}

TABLE II. COEFICIENT OF CORRELATION OF COOPER'S 12 - MinUte Run/ Walk Test With 2- Minute, 4- Minute, 6- Minute, And 8MINUTE RUN/ WALK TESTS

\begin{tabular}{|c|c|}
\hline Test & "r" \\
\hline $8-$ minute Run / Walk Test & $0.78^{*}$ \\
\hline $6-$ minute Run / Walk Test & $0.75^{*}$ \\
\hline 4- Minute Run / Walk Test & $0.68^{*}$ \\
\hline 2- minute Run / Walk Test & $0.47 *$ \\
\hline
\end{tabular}

\section{B. Significant at 0.05 level of confidence}

The findings of statistical analysis as shown in Table 2 revealed that: scores in $2-$ minute Run/ Walk $(r=0.47), 4$ minute Run/ Walk ( $r=0.68), 6$ - minute Run/ Walk $(r=0.75)$, 8- minute Run/ Walk $(r=0.78)$ tests are significantly related to scores in 12- minute Run/ Walk test. But, scores in 8minute Run/ Walk test were found to have the highest correlation with scores in 12- minute run/ Walk Test.

The coefficient of reliability presented in Table 1 shows that the 8 - minute Run/ Walk test have the highest reliability under Test- retest conditions. The remaining tests in descending order of merit being 4- minute, 6- minute, and 2minute Run/ Walk tests.

Despite the statistical significance of correlation with the Criterion test, the 2- minute and 4- minute Run/Walk tests have doubtful concurrent validity; while for the 6- minute and 8- minute run/walk tests, the concurrent validity may be assumed to be acceptable.

\section{CONCLUSIONS}

Within the limitations and conditions of this study, the following conclusions emerge:

1. 6 and $8-$ minute Run/walk tests can be used as substitute for the 12- minute Run/walk Test to measure the cardiovascular endurance of professional male students in physical education.

2. The validity of the 4- minute Run/ walk test as a measure of cardiovascular endurance is questionable.

3. The $2-$ minute Run/walk test is not a suitable substitute for the 12- minute Run/ walk test.

\section{ACKNOWLEDGMENT}

My profound gratitude goes to our Principal for his help, generosity, affection, and invaluable suggestion. Thanks so much..

\section{REFERENCES}

[1] K. H. Cooper, “Aerobics”, New York, Bantom Bodes Inc., (1977).

[2] J. D. Gennarq, "Individualized exercise and optimal physical fitness". Philadelphia, Lea and Fibiger, 1974.

[3] L. F. Morehouse, A. T. Miller, "Physiology of Exercise 7th ed". Saint Louis, The C. V. Mosby Company, 1976.

[4] R. L. Baker, "The effect of the physical education programme (fitness for life) on body composition and cardiovascular endurance of college students". Dissertation Abstracts Inter National, 1976, vol. 36, no. 7 , pp. 4323.

[5] M. Robson, M. "Cardiovascular efficiency of professional students of physical education”. SNIPES Journal, 1978, p. 39.

[6] B. Knechtle, G. Kohler, "Running performance, not anthropometric factors is associated with race success in Triple Iron Triathlon". British Journal of Shorts Medicine, 2009, vol. 43, pp. 437- 441.

[7] M. G. Miller, "Effect of six week plyometric training program on agility". Journal of Science and Medicine, 2006, vol. 5. 